Pre-print version. Final version published as: Amaral, Patrícia. 2018. Expressive meaning. PragmatikHandbuch (Handbook of Pragmatics), ed. by Frank Liedtke and Astrid Tuchen, 325-33. Springer/ Metzler.

\title{
Expressive meaning
}

\section{Introduction}

The term expressivity or expressive meaning has a long tradition in linguistics. Roman Jakobson, building on an earlier proposal by Bühler (1934), coined the term expressive or emotive for one of the functions of language. He describes it as "focused on the ADDRESSER [speaker], aims a direct expression of the speaker's attitude toward what he is speaking about" (Jakobson 1960: 354) and gives interjections as the prime example of this function. The separation between emotive language and referential (or descriptive) language is clear in his characterization of interjections: "they are not components but equivalents of sentences" (Jakobson 1960: 354). Although there is significant overlap between this definition and later ones, later proposals, starting with Cruse (1986), focus on diagnostics that underlie the distinction between expressive meaning and descriptive or truthconditional meaning, i.e. meaning that can be explicitly denied and objectively verified in the actual world (Lyons 1977).

This chapter focuses on Christopher Potts's theory of expressive meaning, a recent proposal that has its roots in Grice's concept of conventional implicature (Grice [1967]1975), the multidimensional view of sentence meaning as tuples of meanings as originally presented in Karttunen and Peters (1979), and the formal approach to "meaning as use" from Kaplan (1999). Coming from a model-theoretic semantic tradition, Potts $(2005 ; 2007)$ provides an ontology of different types of meaning and a compositional account of their possible combinations. The system devised by Potts to model the behavior of expressives is summarized in section 2, which also presents the properties of expressive meaning. Section 3 offers examples of expressive meaning studied in the literature, including lexical and non-lexical expressives. Section 4 discusses some possible challenges to Potts's theory. Section 5 briefly discusses the connection between expressive meaning and language change. Section 6 concludes with a summary of current directions of the research on expressivity.

\section{Expressive meaning and lexical semantics}


Cruse (1986) introduces the term expressive meaning in the context of synonymy in lexical semantics; while (1a) and (1b) convey the same message, their content is put across in different ways (1986: 271, [15a] and [15b]):

(1a) I just felt a sudden sharp pain.

(1b) Ouch!

Cruse points out that (1a) can be challenged by an interlocutor, but doing so with (1b) results in infelicity. He distinguishes between propositional meaning (i.e. truth-conditional) and expressive meaning: "Expressive meaning carried by a lexical item in a statement plays no role in determining its truth-conditions." (Cruse 1986: 271). The two types of meaning can be distinguished by other properties: (i) expressive meaning is analogic (it may vary continuously), while propositional meaning is digital or discrete; (ii) expressive meaning cannot be displaced from the time and place of utterance and is bound to the speaker, unlike propositional meaning, which can be displaced; (iii) expressive meaning cannot be called into question by simple negation, which impinges on the propositional meaning. Lexical items with expressive meaning are exclamative expletives (e.g. Gosh! Wow!), adjectival or adverbial modifiers (e.g. that damn dog, blooming well), taboo expletives (e.g. Holy shit! My arse!), phasal adverbs like already and still, words containing diminutive affixes like $d a d d y$ and mummy, and prosodic contours.

Cruse makes the crucial observation that while some items only have expressive meaning (e.g. expletives like ouch and wow), other items are mixed because they have both, and often form minimal pairs with words that only share their propositional traits. Examples are found in all syntactic categories: e.g. daddy and father, mug and face, baby and infant, jolly and very, put out and issue. According to Cruse, their "meanings differ only in that they express different evaluative judgements on their designated referents (or one expresses a judgment while the other is neutral)... These evaluative traits undoubtedly belong to the same semantic area that is typical of the expressive channel, and some of the evaluative meaning may well be expressive" (277). This effect of "coloring" had already been noted by Frege and called Färbung (Frege 1897/1979). Cruse's seminal observations in this work point to the main properties of expressive meaning and frame them within a classification of different types of meaning: (i) propositional, (ii) expressive, 
(iii) presupposed, (iv) evoked. Several properties of expressive meaning identified by Cruse are central to Potts's theory described in the next section.

\section{Expressives in Potts's logic of the multidimensionality of meaning}

Building on the term and observations from Grice ([1967]1975) on conventional implicatures, Potts proposes a split in the domain of meanings. The territory of entailments or commitments that are not context-dependent contains, besides at-issue entailments, conventional presuppositions and conventional implicatures (henceforth CIs), that Potts considers a distinct class of meanings. Although CIs include a large range of phenomena, they are unified by a set of properties. CIs are (i) conventional implications, i.e. they are not cancellable (unlike conversational implicatures), (ii) they are not-at-issue in the sense that they are not the main contribution of an utterance and hence are "logically and compositionally independent" (Potts 2005: 11) of the at-issue content, although they may take at-issue content as argument(s), (iii) they never take narrow scope over operators like negation, that affect at-issue content, and (iv) they are commitments made by the speaker of the utterance, i.e. they are speaker-oriented. Crucially, conventional implicatures are not contextdependent, they are grammatically encoded commitments and hence they are amenable to a syntactic-semantic treatment. Potts (2005) provides a type-driven logic for this multidimensional theory of meaning, called $L_{C r}$. In this logic there are two types of asserted content, with $e^{a}$, $t^{a}$ and $s^{a}$ used for types of at-issue content and $e^{c}, c^{a}$ and $s^{c}$ used for conventionally-implicated content. Due to space limitations it is not possible to explain all the details of the system introduced in Potts (2005); for a detailed presentation and critical evaluation the reader is referred to Amaral et al. (2007). A proposal that analyzes some shortcomings of the original system and offers a more developed system is Gutzmann (2011).

In Potts's theory of CIs (Potts 2005), there are two types of constructions that fit the criteria for CI-hood: supplemental expressions (appositives and supplemental adverbs) and expressives, the set of constructions we focus on here. In his work Potts uses the terms CIs and expressives to refer both to the class of meanings and to the meaning triggers, a practice followed in this chapter. Potts himself points out that expressives fit best the criteria for CIs, as they are "speaker-oriented comments on a semantic core (at-issue entailments)" (Potts 2005: 11). Examples of expressives discussed by Potts are evaluative adjectives (e.g. damn), epithets (e.g. the jerk), swear words, 
honorifics in Japanese, discourse particles, and the Konjunktiv I in German. The technical details of his theory of expressives is further developed in subsequent work, particularly in two articles published in a special issue of the journal Theoretical Linguistics, Potts (2007a) and (2007b). That proposal is summarized here; the reader is referred to the journal for a complete account and for criticism raised by other authors in that volume.

In his work from 2007 he introduces an expressive type $\varepsilon$ that replaces $c$. According to Potts, expressive content is distinct from other types of content (not just descriptive, but also presuppositional) because it scopes out of operators that affect other implications (e.g. tense operators, conditionals, modal operators), i.e. no syntactic embedding leads to a semantically embedded interpretation. Potts accounts for this empirical generalization in the formal implementation by assuring that the expressive type $\varepsilon$ is only an output type, as in (2d) below. In this system there is no operation that takes an expressive type as input and outputs a descriptive type and it is also not possible for an expressive to take another expressive type as argument. The semantic types are as follows (from Potts 2007: 183 [36]):

(2) a. $e$ and $t$ are descriptive types.

b. $\varepsilon$ is an expressive type.

c. If $\sigma$ and $\tau$ are descriptive types, then $\langle\sigma, \tau\rangle$ is a descriptive type.

d. If $\sigma$ is a descriptive type, then $\langle\sigma, \varepsilon\rangle$ is an expressive type.

e. The set of types is the union of the descriptive and expressive types.

With respect to the denotation of expressives, in Potts $(2007 \mathrm{a}, \mathrm{b})$ the author models the content of expressives by introducing expressive indices, defined as in (3):

(3) Expressive indices are triples $\langle a \mathbf{r} b>$, where $a$ and $b$ are individuals and $\mathbf{r}$ is an interval in [$1,1]$ registering the intensity of expressive feeling that $a$ has towards $b$ as well as its degree of positivity or negativity...The set of indices that makes its way into the context provides that context's expressive setting, and new language can heighten emotions by narrowing the current indices' intervals or introducing new ones. (Potts 2007b: 256) 
Under this view, the contribution of expressives is to affect the set of expressive indices, one of the parameters of the context (which is conceived as a tuple also including the speaker, time of utterance, world of evaluation, and contextual judge in the sense of Lasersohn 2005). By altering the "expressive setting" the speaker introduces either a positive or a negative attitude towards an entity in the discourse. Crucially, this behavior is constrained by consistency; in this system a felicitous or infelicitous utterance is modelled by the availability of only one expressive index for each salient pair of entities $a$ and $b$.

This proposal, in particular the expressive indices, has sparked considerable criticism. For discussion of technical problems and enrichments of this proposal the reader is referred to Zimmermann (2007) and Potts's response (Potts 2007b).

\subsection{Properties of expressive meaning}

\subsubsection{Independence}

Expressive content is separate from descriptive, truth-conditional meaning. This property underlies the existence of two different semantic types in Potts's multidimensional logic, as shown above. Independence relies on the notion of deniability: the truth-conditional content of an expression may be challenged, i.e. questioned or negated, without affecting its expressive meaning. So in (4), it is possible to confirm or deny the proposition that Krege is famous without committing to the content that Krege is a bastard. Informally, the separation between the truth-conditional content and the evaluation conveyed by (4) can be given as in (5):

(4) That bastard Krege is famous. (from Potts 2007: 168)

(5) a. Descriptive: Kresge is famous

b. Expressive: Kresge is a \{bastard/bad in the speaker's opinion\}

Importantly, the meaning of (4) is not a conjunction of propositions at the descriptive level, but rather a combination of two meaning components that belong to different levels. The behavior of the two components is different; the expressive meaning is not part of what is questioned in (6), as shown by the infelicity of the reply in (6b).

(6) A: Is that bastard Krege famous? 
a. B: Yes; everyone knows him.

b. B: Yes, \#he really is a bastard.

Expressive content cannot be denied by simple negation, as shown by the contrast in acceptability between (7a) and (7b), negative replies to the question in (6):

(7) a. No, that's not true. Not many people know him.

b. No, that's not true. \#He is a wonderful person.

Another example of independence, is provided by ethical datives, i.e. non-argumental dative pronouns that convey the speaker's attitude or emotive state towards a certain proposition. These forms are attested in several languages, e.g. Spanish, German, Hebrew (Gutzmann 2007, Borer and Grodzinsky 1986).

(8) El niño no me duerme.

'The child won't fall asleep (and I am upset about that).'

(9) Schreib mir schön deine Hausarbeit! (Gutzmann 2007: 3)

'Do write your homework (as I am invested in your doing that)!'

As in the previous examples, it is possible to separate the truth-conditional content of these sentences from their expressive meaning. In the case of (8) and (9) the bolded pronouns may be deleted from the sentence without affecting its truth conditions, as they convey the attitude of the speaker towards the propositional (i.e. descriptive) content. Note that compositionally the expressive takes the descriptive content, i.e. the proposition expressed by the sentence obtained by removing the dative pronoun, as an argument.

Independence sets apart expressives from presuppositions; while truth-conditional meaning may depend on presupposition satisfaction, it is not affected by expressive meaning.

2.1.2 Nondisplaceability and immediacy 
These properties are presented together here because they are closely connected. Both rely on the deictic nature of expressives, i.e. they are "valid only for the utterer, at the time and place of utterance" (Cruse 1986: 272). Expressives achieve an effect by virtue of being uttered in a specific context. Potts defines nondisplaceability as follows:

(10) Nondisplaceability: Expressives predicate something of the utterance situation. (Potts 2007a: 166)

Expressive meaning cannot be displaced in the sense that it cannot be evaluated at a time different from the time of speech or with respect to other worlds or parameters of evaluation (e.g. as in modal and conditional sentences, or under attitude predicates). For example, one cannot say ouch or oups in the past. This is only possible in so-called free indirect speech, a type of speech that displaces the evaluation to an agent who is a speaker in a previous utterance being reported. Such examples have been used as basis for criticism of nondisplaceability (Amaral et al. 2007), suggesting instead that expressives (and CIs in general) are indexical elements, which shows a related property of expressives, namely perspective dependence, a property discussed in 2.1.4.

Expressives have performative import and in this respect display immediacy, i.e. "the act of uttering an expressive morpheme is sufficient for conveying its content." (Potts 2007a: 180). Once the expressive has been uttered, the context has been altered, and hence it is very difficult for the speaker to distance herself from the implications of the expressive, as shown by several examples presented by Potts. Potts builds on the parallel between expressive terms and speech acts to show that it is equally nonsensical to deny a speech act that has been made and to deny an expressive. This property also explains the difficulty to render the content of an expressive in descriptive terms, the next property to be discussed in 2.1.3.

The ability of expressive meaning to perform, i.e. to act upon the interlocutor is already pointed out by Cruse: "[T]hey actually, in a sense, express aspects of situations, and can therefore help to create them. For instance, a speaker can establish a relation of intimacy with a hearer merely by choosing one lexical item rather than another in the course of a conversation." (Cruse 1986: 285). In Potts's formal system, this property is accounted for by the fact that an expressive contributes a change in the expressive setting of a context, as shown in (3) above. In his system, 
Potts does this by making denotations of expressives alter one of the context parameters, something that normal semantic denotations cannot do (Potts 2007a: 184, 188).

\subsubsection{Descriptive ineffability}

Potts argues that expressives are ineffable; when asked to paraphrase the content of an expressive, native speakers resort to instances in which the expressive is appropriately used because they cannot find an appropriate definition. That is to say, the meaning of an expressive is best conveyed by fleshing out the conditions it places on contexts of use (Kaplan 1999). Potts argues that expressive content is not propositional and invokes studies showing that there is neurological evidence that expressive language is located in a different area of the brain from other types of content, as shown by patients with lesions in certain brain areas (Jay 2000, Van Lancker and Cummings 1999). In Potts's system, modelling the denotation domains of expressives as mappings from one context tuple to another (i.e. expressives achieve an update of the context's expressive setting) provides the formal way to account for the meaning of expressives without using propositional content. While this property seems to be particularly true for expressives like epithets, swear words and evaluative adjectives it may be more problematic for modal particles and phasal adverbs, as discussed below.

Geurts (2007) has questioned the descriptive ineffability of expressives by arguing that many words are hard to paraphrase; the meaning of words like the, because, languid is difficult to explain as well, and yet these words are not classified as expressive. He claims, then, that "[d]escriptive ineffability doesn't draw the line between descriptive and expressive language" (Geurts 2007: 210).

\subsubsection{Perspective-dependence}

A crucial property of expressive content is that it is evaluated from a certain point of view, which tends to be that of the speaker but may be shifted given appropriate contextual conditions (i.e. if another individual is salient enough in the context). In Potts's original description of the properties of CIs he states that "These commitments are made by the speaker of the utterance "by virtue of the meaning of' the words he chooses." (Potts 2005: 11) 
One of the diagnostics for this property is embedding under an attitude predicate or verba dicendi, as in (11). The commitment that Krege is a bastard conveyed in the complement clause is not attributed to the subject of the sentence (Sue) but rather to the speaker.

(11) Sue believes that that bastard Krege should be fired. (\#I think he's a good guy.)

Subsequent work has shown that expressives (as well as other types of CIs) allow for perspectiveshifting (Amaral et al. 2007, Anand 2007), which has been confirmed by experimental evidence (Harris and Potts 2009, Kaiser 2015, a.o.). In order to capture this fact, Potts has built on Lasersohn's work on predicates of personal taste (Lasersohn 2005) to incorporate the contextual judge as a parameter of the utterance context (Potts 2007a). There is a growing body of research on the role of different types of expressions favoring perspective shifts, e.g. epithets and epistemic adverbs (see Kaiser 2015).

\subsubsection{Repeatability}

Expressive content can be repeated in order to strengthen the emotive effect of the utterance, while repetition leads to redundancy or infelicity in the case of descriptive content. An example is the contrast between (12) and (13), using examples from Potts (2007a):

(12) Damn, I left my damn keys in the damn car.

(13) \#I'm angry! I forgot my keys. I'm angry! They are in the car. I'm angry!

Potts justifies the difference between (12) and (13) through the descriptive ineffability property of expressives, as well as the analogical character of expressives mentioned by Cruse.

While this property applies well to interjections and swear words, it may not apply across the board for the range of expressions classified under expressives. For instance, as pointed out by Potts himself, in the domain of honorifics, in multiple utterances the use of honorifics is constrained by rules and repeated use does not necessarily convey a stronger attitude of respect or social distance. Additionally, the repeated use of adjectives may have a compositional interpretation at the descriptive level (as in big big big apple) and the repeated use of nouns may convey descriptive meaning (e.g. SALAD- salad, cf. Ghomeshi et al. 2004).

The properties immediacy, descriptive ineffability, and repeatability are related because they make expressives similar to certain forms of non-verbal communication; they are reminiscent 
of “a smile, a frown, a gesture of impatience" (Cruse 1986: 272). This supports Potts's contention that expressives are a distinct class of meanings. However, this class looks more heterogeneous than Potts presents it, especially if one tries to apply the diagnostics reviewed above beyond the commonly used examples of epithets and slurs. The range of phenomena classified under expressives is presented in the next section and then we address some of the possible criticisms of Potts's theory of expressive meanings.

\section{Examples}

This section offers a non-exhaustive list of examples of expressives; it will show the wide range of constructions covered by the term. Potts (2005) repeatedly points to the lexicality of expressives: this class of meanings is conventionally encoded and hence amenable to a treatment as part of the "grammar", for example as part of the meaning of individual lexical items.

\subsection{Lexical}

Among lexical items that instantiate expressive content, interjections (e.g. ouch, wow) and epithets (e.g. that idiot) stand out; they are purely expressive because they do not contribute descriptive content. In Spanish, a good example is provided by the constructions in (14) containing evaluative adjectives:

(14) el tonto de Pepe, el gilipollas de tu vecino, el estúpido de mi jefe 'that idiot Pepe, your douchebag neighbor, my stupid boss'

Another example is lexical pejoratives, in particular ethnic slurs, e.g. nigger, chink, jap, Kraut (Gutzmann 2015, Finkbeiner et al. 2016). These examples differ from epithets in that they have both a truth-conditional denotation (the nationality or race of a certain group of people) and an expressive meaning (the negative racist attitude of the speaker towards that group of people).

Honorifics are also prime examples of expressives; they are "special linguistic forms that are used as signs of deference toward the nominal referents or the addressee" (Shibatani 1998: 341). These forms convey social meaning (they express relationships between interlocutors in a codified manner). Shibatani presents two main types of honorifics, referent honorifics (the most widespread type of system, which may include titles, pronominal forms, nouns) and addressee 
honorifics. For example, in Japanese the latter may not be lexical, i.e. it may be a special verbal ending - mas, but respect towards the addressee can also be shown by using a humbling verbal form through a suppletive verb (e.g. the suppletive form mairu instead of the verb iku 'go'). Interestingly, many honorific expressions are iconic to their meaning of social distance: "the longer the form, the politer the expression" (Shibatani 1998: 346) and their use may also be accompanied by physical distance between the interlocutors in the communicative situation.

Some discourse particles (e.g. German modal particles, see Gutzmann 2015; Amaral and Del Prete 2017) are sometimes mentioned as examples of expressives, although their status is not always clear (see section 4).

\subsection{Non-lexical examples}

Expressive content may be conveyed by elements below the word level, through affective or expressive morphology (Zwicky and Pullum 1987), like derivational suffixes that create diminutives and augmentatives. The former are exemplified by (15) and (16), from European Portuguese:

(15) Está aqui quentinho.

'It's nice and warm in here'.

(i) It is warm in the place of utterance.

(ii) The speaker has a positive attitude towards (i).

The sentence in (15) contributes multidimensional meaning, as shown by the paraphrase of its meaning components in (i) and (ii). The meaning of (16) is more complex in that it involves the speaker's recognition of the power and social standing of the addressee:

(16) Vai um cafezinho?

(i) Would you like a coffee?

(ii) The speaker respects the addressee.

Sentence (16) can be compared to a humbling honorific; the suffix does not apply to the referent but rather denotes the attitude of respect of the speaker towards the addressee. 
Other examples of word formation, both through compounding and derivation, may convey expressive content, as shown by the German pejorative morphology in (17)-(19), from Finkbeiner et al. (2016: 2-3):

(17) sau- (Saupreusse, sauschlecht) 'sow Prussian', 'sow bad'

(18) - arsch (Politikerarsch) 'politician arse'

(19) - erei (Lauf-erei 'running around')

Morphology may also convey expressive meaning through number; Corbett (2000: ch. 7) mentions affective uses of the plural. For example, in honorific speech, plural forms may be used to a single addressee to convey respect (see Corbett 2000: 7.1, also Shibatani 1998). Other uses of the plural involve the expression of intensification or exaggeration, often to convey the speaker's negative attitude towards some situation, especially when context shows that the referent is singular, as in (20) from Slovene:

(20) Kdo krade denarnic-e?

Who steals purse-PL

'Who keeps stealing purses?'

This function of number is related to morphological forms that indicate an excessive number, known as "plurals of abundance" (see also Amaral 2013 for an exploration of evaluative uses of plural in the nominal and verbal domains).

Beyond the segmental level, a much discussed source of expressive content is prosody, as used for irony and sarcasm (Finkbeiner et al. 2016). Another well-studied examples is the so-called exclamative or unexpectedness intonation (Gutzmann 2015 and references therein), as in (21) that combines syntactic and prosodic rules.

(21) How TALL Michael is!

Sentence (21) expresses the speaker's surprise towards Michael's height, implying that it is unexpected. 
4. Challenges and "margins" of expressive meanings

Potts defines expressives as meanings and meaning triggers with the set of properties presented above. However, while swear words and interjections are easy to classify, cases are less obvious. I briefly present some challenges to Potts's theory (see the volume of Theoretical Linguistics for a more developed discussion).

Are there terms that are expressive to a lesser degree, i.e. could they meet some of the criteria presented above but not all? Potts (2007) mentions the case of lurk and few stating that they do not meet any of the defining criteria of expressives. The domain of expressives may then exclude lexical items that are associated with lexical "coloring" or commitments that can be attributed to the subject of the sentence but not to the speaker. A related issue is whether register differences belong within expressive meaning. Differences between pairs of apparent synonyms, as pointed out by Cruse (1986), often rely on register distinctions. A more radical situation is described by Shibatani, who mentions Javanese as a language with ten speech levels or "registers" that are determined by speech situation and the social categories of the interlocutors, like age differences, social status, and degree of familiarity (Shibatani 1998: 349).

Another case in point is that of discourse particles. Potts states that still, even, and but "play supportive roles" (Potts 2008: 1) to expressive meaning but is vague about their classification. Do all discourse particles convey expressive meaning? As pointed out by Löbner, phasal adverbs have multidimensional meaning. Should one of their components be considered expressive? In the case of phasal adverbs the meaning components are propositional, hence different from prime examples of expressives. Can expressives have propositional content? Additionally, properties like nondisplaceability and immediacy may not apply in the same way as they do to interjections and epithets. It is clear that modal particles constrain their contexts of use without affecting the truth conditions of the sentence but those restrictions are not ineffable in the sense discussed above; they can be fleshed out in terms of the speaker's expectations and shared knowledge about the common ground of speaker and hearer (for an example, see Amaral and Del Prete 2017). This issue pertains to the relation between expressives and use-conditional meaning in the sense of Gutzmann (2015). The properties of expressives identified by Potts partly overlap with the concept of use-conditional meaning, particularly with content that is not propositional. 
An aspect not accounted for by the theory is the fact that expressives often display positive as well as negative uses, an observation made in Geurts (2007). Why does expressive meaning have this property and how can it be formally implemented?

An important criticism to Potts's earlier work pertained to relations between types of meaning, particularly concerning independence (Amaral et al. 2007). Although this work focused on instances of supplemental expressions that are not speaker oriented, there are also examples of expressives showing that feature, showing that the property of independence may need to be further refined. For example, implications drawn from truth-conditional content may influence the interpretation of expressives by contributing to identifying whose perspective the expressive content depends on (or who is the judge, in Lasersohn's terms), as in (22):

(22) After Maia found out her dad had initiated the Ponzi scheme and lied to her, she began hating the jerk and his image now chased her everywhere. I personally think her dad is not a jerk.

The descriptive content of the temporal clause in (22) affects the interpretation of the expressive the jerk, which is seen from the perspective of the subject, like the indexical now in the sentence. Examples like (22) not only confirm the perspective dependence of expressives but also show that independence, as conceived by Potts, may be problematic. Although the two meaning dimensions may be independent, at the pragmatic level they may be related (as argued already by Amaral et al. 2007).

In his criticism of Potts's theory of expressives, Geurts writes: "If expressive words were radically different from descriptive ones...it would come as something of a surprise that they underlie the same processes of meaning change." Geurts (2007: 211) Geurts mentions the word bastard, originally meaning 'person born out of wedlock', which later acquired a primarily expressive meaning 'unpleasant or despicable person'. In fact, this very example shows that descriptive and expressive meaning pattern differently with respect to language change, as discussed in the next section.

5. Expressive meanings and language change 
Studies of semantic change have shown that words and constructions originally conveying descriptive content may increasingly acquire expressive components over time, but the inverse pattern is generally not found. This tendency was originally identified by Traugott (1986), who called it subjectification, defined in (23). This generalization is found across a range of phenomena, including modal verbs, subject-oriented adverbs, and discourse markers.

(23) "Over time, meanings tend to come to refer less to objective situations and more to subjective ones (including speaker point of view), less to the described situation and more to the discourse situation" (Traugott 1986: 540)

A large body of work confirms this tendency, and the connection with multidimensionality of meaning has recently been established, for example through the development of English totally from a lexical intensifier to an epistemic marker that conveys social meaning (cf. Beltrama 2016). From a Gricean point of view, this tendency has been explained through the conventionalization of conversational inferences: speaker's commitments towards the situation being described that initially arise contextually may become conventionally encoded (Traugott and Dasher 2005).

Additionally, items that convey a positive or a negative evaluation may over time come to convey the opposite evaluation, i.e. from positive to negative (a process traditionally called pejoration in historical linguistics) and from negative to positive (amelioration). While these processes differ from the tendency in (23), they affect evaluative meanings and confirm, from a historical perspective, the ability of expressive language to shift between positive and negative poles. In sum, the behavior of expressive meaning vis-à-vis descriptive meaning with regards to language change provides additional support for treating expressives as a distinct class of meanings.

\section{Conclusion}

In this chapter I have shown the properties of expressive meaning as understood in Potts $(2005,2007 \mathrm{a}, \mathrm{b})$. I have also mentioned possible criticisms to this theory as well as further evidence for this class of meanings; through semantic change these speaker's commitments become part of the conventional meaning of words and hence encoded in the grammar. 
Current explorations of expressive meaning go in two main directions: (i) experimental approaches, for example by investigating the processing as well as perspective-dependence of this type of meaning, and (ii) the relation between expressive meaning and other types of meaning, like social meaning. Additionally, studies in this area highlight the social relevance of expressives, both with respect to hate speech and political issues and with respect to sentiment analysis and data mining.

\section{References}

Amaral, Patrícia (2013): The pragmatics of number: The evaluative properties of vivir + V[Gerund]. In: Journal of Pragmatics 51, 105-21.

Amaral, Patricia / Del Prete, Fabio (2017): Modality, presupposition and discourse: The meaning of European Portuguese afinal and Italian alla fine. In: Ruth Lopes/ Juanito Ornelas de Avelar/Sonia M. Cyrino (Hg.): Selected Papers from the $45^{\text {th }}$ Linguistic Symposium on Romance Languages (LSRL). Campinas, Brazil, 2-13.

Amaral, Patrícia, Craige Roberts, and E. Allyn Smith (2007): Review of 'The Logic of Conventional Implicatures' by Chris Potts. In: Linguistics and Philosophy 30, 707-49.

Beltrama, Andrea (2016): Bridging the Gap: Intensifiers between Semantic and Social Meaning. Dissertation, University of Chicago.

Borer, Hagit / Yosef Grodzinsky (1986): Syntactic cliticization and lexical cliticization. The case of Hebrew dative clitics. In: Hagit Borer (Hg.) The syntax of pronominal clitics. New York, $175-217$.

Corbett, Greville G. (2000): Number. Cambridge.

Cruse, D. Alan (1986): Lexical semantics. Cambridge.

Finkbeiner, Rita, Jörg Meibauer, and Heike Wiese (2016): What is pejoration, and how can it be expressed in language? In: Rita Finkbeiner/Jörg Meibauer (Hg.): Pejoration. Amsterdam, 120.

Ghomeshi, Jila, Ray Jackendoff, Nicole Rosen and Kevin Russell (2004): Contrastive focus reduplication in English (The salad-salad paper). In: Natural Language and Linguistic Theory 22, 307-357.

Gutzmann, Daniel (2007): Eine Implikatur konventioneller Art: Der Dativus Ethicus. In: Linguistische Berichte 211, 277-308.

Gutzmann, Daniel (2011): Expressive modifiers and mixed expressives. In: Oliver Bonami/ Patricia Cabredo Hofherr (Hg.): Empirical Issues in Syntax and Semantics 8, 123-141.

Gutzmann, Daniel (2015): Use-Conditional Meaning. Studies in Multidimensional Semantics. Oxford.

Harris, Jesse A. and Christopher Potts (2009): Perspective-shifting with appositives and expressives. In: Linguistics \& Philosophy 32, 523-552. 
Jakobson, Roman (1960): Closing statements: Linguistics and Poetics. In: Sebeok Thomas Albert/John W. Ashton (Hg.): Style in Language. New York, 350-377.

Jay, Timothy. (2000): Why We Curse: A Neuro-psycho-social Theory of Speech. Philadelphia.

Kaiser, Elsi (2015): Perspective-shifting and free indirect discourse: Experimental investigations. In: Proceedings of SALT 25, 346-372.

Karttunen, Lauri and Stanley Peters (1979): Conventional implicature. In: Choon-Kyu Oh/David A. Dinnen (Hg.): Syntax and Semantics 11: Presupposition, New York, 1-56.

Lasersohn, Peter (2005): Context dependence, disagreement, and predicates of personal taste. In: Linguistics and Philosophy 28, 643-686.

Lyons, John (1977): Semantics. Cambridge.

Potts, Christopher (2005): The Logic of Conventional Implicatures. Oxford.

Potts, Christopher (2007) a: The expressive dimension. In: Theoretical Linguistics 33, 165-197.

Potts, Christopher (2007) b: The centrality of expressive indices. In: Theoretical Linguistics 33, 255-268.

Potts, Christopher and Shigeto Kawahara (2004): Japanese honorifics as emotive definite descriptions. In Kazuha Watanabe/Robert B. Young (Hg.): Proceedings of the 14th Conference on Semantics and Linguistic Theory. Ithaca, NY, 235-254.

Traugott, Elizabeth Closs (1986): From polysemy to internal semantic reconstruction. In Vassiliki Nikiforidou/Mary Niepokuj/Deborah Feder (Hg.): Proceedins of the $12^{\text {th }}$ Annual Meeting. Berkeley, 389-405.

Traugott, Elizabeth Closs and Richard Dasher (2005): Regularity in semantic change. Cambridge.

Shibatani, Masayoshi (1998): Honorifics. In Jacob Mey (Hg.): Concise encyclopedia of pragmatics. Amsterdam/New York, 341-350.

Van Lancker, Diana and Cummings, J.L. (1999): Expletives: Neurolinguistic and neurobehavioral perspectives on swearing. In: Brain Research Reviews 31, 83-104.

Zwicky, Arnold \& Geoffrey K. Pullum (1987): Plain morphology and expressive morphology. In: Proceedings of the Thirteenth Annual Meeting of the Berkeley Linguistics Society, 330-340. 